\title{
Correlation between ELF-PEMF exposure and Human RPE Cell Proliferation, Apoptosis and Gene Expression
}

\author{
Morteza Oladnabi ${ }^{1,2, a}$, PhD; Mohammad Amir Mishan ${ }^{3, a}$, MS; Mozhgan Rezaeikanavi ${ }^{3}$, MD \\ Mehryar Zargari ${ }^{4}$, PhD; Rouhallah Najjar Sadeghi ${ }^{4}$, PhD; Abouzar Bagheri ${ }^{4}$, PhD \\ ${ }^{1}$ Stem Cell Research Center, Golestan University of Medical Sciences, Gorgan, Iran \\ ${ }^{2}$ Ischemic Disorders Research Center, Golestan University of Medical Sciences, Gorgan, Iran \\ ${ }^{3}$ Ocular Tissue Engineering Research Center, Research Institute for Ophthalmology and Vision Science, Shahid Beheshti \\ University of Medical Sciences, Tehran, Iran \\ ${ }^{4}$ Department of Clinical Biochemistry and Medical Genetics, Molecular and Cell Biology Research Center, Faculty of Medicine, \\ Mazandaran University of Medical Sciences, Sari, Iran \\ ${ }^{a}$ Both authors contributed equally to the manuscript \\ ORCID: \\ Morteza Oladnabi: https://orcid.org/0000-0001-7037-5084 \\ Mohammad Amir Mishan: https://orcid.org/0000-0001-8210-9322 \\ Abouzar Bagheri: https://orcid.org/0000-0001-8040-5056
}

\section{Abstract}

Purpose: Emerging evidence implies that electromagnetic fields (EMFs) can negatively affect angiogenesis. In this regard, the effects of extremely low frequency pulsed electromagnetic field (ELF-PEMF) exposure on the relative expression level of angiogenic factors involved in the pathogenesis of ocular disorders were evaluated in human retinal pigment epithelial (hRPE) cells in order to investigate a noninvasive therapeutic method for patients with several ocular diseases associated with neovascularization.

Methods: After separating hRPE cells from globes, hRPE cells were exposed to $15 \mathrm{mT}$ of ELF-PEMF $(120 \mathrm{~Hz})$ at 5, 10, and 15 min for seven days. Cell proliferation and apoptosis of treated cells were evaluated via ELISA assay. Moreover, relative expression changes of HIF-1 $\alpha$, CTGF, VEGFA, MMP-2, cathepsin D, and E2F3 were performed using real-time RT-PCR.

Results: ELF-PEMF exposure had no significant effects on the apoptosis and proliferation rate of hRPE cells. Expression level of HIF-1 $\alpha$, CTGF, VEGFA, MMP2, cathepsin D, and E2F3 was downregulated following $5 \mathrm{~min}$ of ELF-PEMF exposure.

Conclusion: As ELF-PEMF showed inhibitory effects on the expression of angiogenic genes in hRPE cells with no cytotoxic or proliferative side effects, it can be introduced as a useful procedure for managing angiogenesis induced by retinal pathogenesis, although more studies with adequate follow-up in animal models are needed.

Keywords: Angiogenic Factors; ELF-PEMFs; hRPE Cells

J Ophthalmic Vis Res 2021; 16 (2): 202-211 


\section{INTRODUCTION}

Neovascularization, a process of forming new vessels occurs during physiological development and also pathological events, involved in several ocular diseases such as age-related macular degeneration (AMD), ischemic retinal vein occlusion, glaucoma, corneal neovascularization secondary to chemical injury or infection, diabetic retinopathy (DR), and inflammatory processes. ${ }^{[1-3]}$ Through the production of different fibrotic and angiogenic factors in choroidal neovascular membranes, retinal pigment epithelial (RPE) cells contribute to choroidal neovascularization (CNV) and paracrine signaling between choriocapillaris and RPE layer. ${ }^{[4-7]}$ Hypoxia is an important regulator of cell migration and angiogenesis, especially under pathologic conditions, which perform its action by upregulating hypoxiainducible factor 1 (HIF-1) and vascular endothelial growth factor A (VEGFA). ${ }^{[8-11]}$ VEGFA mainly regulates angiogenesis, contributing to the migration and proliferation of vascular endothelial cells and tube formation, which increase vascular permeability in angiogenesis. ${ }^{[12]}$ The VEGF/VEGFR signaling pathway is involved in the activation of multiple angiogenic factors, including matrix metalloproteinases (MMPs), cathepsins, connective tissue growth factor (CTGF), and E2Fs. ${ }^{[13,14]}$ CTGF can help regulation of the extracellular matrix (ECM) turnover and a relationship is found between CTGF and CNV. ${ }^{[15]}$ In addition, matrix-degrading proteinases including MMPs and cathepsins induce angiogenesis through facilitating endothelial cell penetration in the subendothelial matrix. ${ }^{[16,17]}$

Suppression of relative angiogenic factors in ocular pathologic conditions can prevent angiogenesis and visual impairment. ${ }^{[19,20]}$ In

Correspondence to:

Abouzar Bagheri, PhD. Department of Clinical Biochemistry and Medical Genetics, Molecular and Cell Biology Research Center, Faculty of Medicine, Mazandaran University of Medical Sciences, Sari, Iran. Email: a.bagherimg@gmail.com

Received: 05-11-2019 Accepted: 22-09-2020

Access this article online

Website: https://knepublishing.com/index.php/JOVR

DOI: 10.18502/jovr.v16i2.9084 the treatment of proliferative ocular diseases, anti-VEGF is applied as an intraocular agent. $^{[21]}$ Besides, in many studies, HIF-1 ${ }^{[22]}$ and $\mathrm{MMPs}^{[23]}$ was introduced as therapeutic targets for retinal-related neovascularization diseases

Several studies have shown that electromagnetic fields can be used as therapeutic options, implicating the biological effects of extremely low frequency pulsed electromagnetic fields (ELF-PEMFs) with respect to their amplitude, frequency, and exposure time. ${ }^{[24-26]}$ Many investigations have demonstrated the effects of ELF-PEMFs on the apoptosis, proliferation, differentiation, angiogenic and metastatic properties of different cells. ${ }^{[27-29]}$ This study aimed to determine the ELFPEMF effects on the angiogenic factors in human RPE (hRPE) cells in different exposure times.

\section{METHODS}

\section{Sample Preparation and Cell Culture}

Four eye globes from four human neonatal donors with the age of 2-12 months and death enucleation time of $<24 \mathrm{hr}$, were provided by the Central Eye Bank of Iran. Then posterior segments were cut by removing the iris and vitreous body carefully. Thereafter, the sensory retina was removed after the posterior eyes were dissected into four quadrants. After removing the $\mathrm{RPE} /$ choroid layer from the sclera, incubation was carried out for $60 \mathrm{~min}$ in $2 \%$ dispase solution with $5 \% \mathrm{CO}_{2}$ at $37^{\circ} \mathrm{C}$. Then, centrifugation was performed at $300 \mathrm{~g}$ for five min at $4^{\circ} \mathrm{C}$ in order to achieve cell pellet. Cell pellet was cultured in $25 \mathrm{~cm}^{2}$ flasks with DMEM/F12 medium (SigmaAldrich, Germany), supplemented with 10\% FBS at $37^{\circ} \mathrm{C}$ with $5 \% \quad \mathrm{CO}_{2}$. Finally, the confluent cells from passages 2-5 were used for all the experiments.

This is an open access journal, and articles are distributed under the terms of the Creative Commons Attribution-NonCommercial-ShareAlike 4.0 License, which allows others to remix, tweak, and build upon the work non-commercially, as long as appropriate credit is given and the new creations are licensed under the identical terms.

How to cite this article: Oladnabi M, Mishan MA, Rezaeikanavi M, Zargari M, Sadeghi RN, Bagheri A. Correlation between ELF-PEMF exposure and Human RPE Cell Proliferation, Apoptosis and Gene Expression. J Ophthalmic Vis Res 2021;16:202-211. 


\section{Immunocytochemistry}

Immunocytochemistry with hRPE cell-specific antibodies was performed in order to characterize hRPE cells from the donated eyes. After culturing the hRPE cells at $5 \times 10^{3}$ cells/well in 24-well plates, they were fixed by methanol $\left(-10^{\circ} \mathrm{C}\right)$ at room temperature for $10 \mathrm{~min}$. Then, the cells were permeabilized using Triton X-100 $(0.25 \%)$ and blocked with $1 \%$ bovine serum albumin in PBS at room temperature for 60 min.

After irrigating with PBS to remove the blocking agent, the cells were incubated with a 1:1000 mouse monoclonal IgG2a anti-human cytokeratin $8 / 18$ antibody labeling epithelial cells, as well as a 1:100 rabbit polyclonal IgG anti-human RPE65 antibody labeling RPE microsomal membranes (Santa Cruz, CA, USA) overnight at $4^{\circ} \mathrm{C}$. The fluorescein isothiocyanate (FITC)-conjugated antibodies (1:100 goat anti-mouse and antirabbit IgGs; Santa Cruz, CA, USA) were added for $45 \mathrm{~min}$ in darkness at room temperature following irrigation with PBS. Finally, to stain the nucleus, the cells were incubated with 1.5 $\mathrm{mg} / \mathrm{ml}$ of DAPI (Santa Cruz, CA, USA) for 10 min. To capture images of the labeled cells, an inverted fluorescence microscope (Olympus IX71, Japan) was used with two filters for FITCconjugated antibodies and DAPI (520 and 460 $\mathrm{nm}$, respectively).

\section{ELF-PEMF Treatment}

Similar to previous studies on PEMFs, an exposure system was provided by Shahid Beheshti University of Medical Sciences (Department of Nuclear Medicine, Tehran, Iran). The magnetic field device contains a controller, and Helmholtz coils consisted of two parallel identical coils $(22$ $\mathrm{cm}$ apart) at $22 \mathrm{~cm}$ radius of the curvature. Each coil was constructed by winding 800 turns of 1-mm insulated soft copper wire. The flasks with the confluent hRPE cells was placed between the polar faces of the coils at $37^{\circ} \mathrm{C}$ with $5 \% \mathrm{CO}_{2}$, and exposure time on each day was 5, 10, and $15 \mathrm{~min}$ for three cultures. The experiment was performed at a magnetic intensity of $15 \mathrm{mT}$ (120 $\mathrm{Hz}, 92 \mathrm{~V}$ ) during one week. Immediately after exposure, ELISA assays and RNA extraction were done.

\section{ELISA Cell Proliferation and Cell Death Assays}

Following ELF-PEMF exposure to the cultured hRPE cells, proliferation and apoptosis of cells were assessed using ELISA BrdU and ELISA PLUS kits (Roche, Germany) based on the instructions, respectively. For this experiment, the cultured hRPE cells in passage two were used at a cell density of $1 \times 10^{3} / \mathrm{ml}$ in a 96 -well plate. Proliferation and apoptosis assays of treated cells and control cells were performed in triplicate per cultivated hRPE cell from each donated eye. With respect to cell death ELISA assay, the reading results of the ELF-PEMF-treated cells were compared to the untreated cells and the positive control (a complex of DNA and histone) included in the kit. Absorption of the samples was read at specific wavelengths, using an ELX 808 absorbance reader (BioTek Instruments, VT, USA).

\section{RNA Isolation and Real-Time RT-PCR}

In order to analyze gene expression changes of HIF-1 $\alpha$, CTGF, VEGFA, MMP-2, cathepsin-D, and E2F3 in ELF-PEMF-treated hRPE cells total RNA extraction of the treated and control cells was performed by TRIzol reagent (Ambion, USA). The cells were incubated for five min using TRIzol at room temperature. After adding chloroform to separate RNA, isopropanol (500 ll) was added for RNA precipitation and rinsed with $75 \%$ ethanol. Finally, using nuclease-free water, RNA pellet was dissolved. Spectrophotometry analysis was performed using a NanoDrop (Thermo Fisher Scientific, USA) to determine the concentration and purity of the extracted RNAs (A260/280 concentrations). RNA integrity was evaluated by clearly observing $28 \mathrm{~S}$ and $18 \mathrm{~S}$ rRNA bands using agarose gel electrophoresis.

The SuperScript reverse transcriptase kit and oligo dT primers (Invitrogen, USA) were used for reverse transcription synthesis of the extracted RNAs in both treated and control cells. Afterward an EvaGreen master mix (Solis BioDyne, Estonia) was used for real-time RT-PCR assay. Specific primers for relative genes and GAPDH, as a housekeeping gene, were used, and efficiency (E) was evaluated for each primer according to the slope of the standard curve. Table 1 presents the primer sequences. 
Table 1. Primers used in real-time RT-PCR analysis

\begin{tabular}{lrr}
\hline Name & Forward & Reverse \\
\hline GAPDH & ACAGTCAGCCGCATCTTC & CTCCGACCTTCACCTTCC \\
VEGFA & ACTTCTGGGCTGTTCTCG & TCCTCTTCCTTCTCTTCTTCC \\
CTGF & GCAGGCTAGAGAAGCAGAGC & ATGTCTTCATGCTGGTGCAG \\
MMP-2 & TGGCAAGTACGGCTTCTGTC & TTCTTGTCGCGGTCGTAGTC \\
E2F3 & GAAAGCCCCTCCAGAAACAAG & GCTATGTCCTGAGTTGGTTGAAG \\
HIF-1 $\alpha$ & AACTGGAGACACAATCATATCTTTAG & TTCAGCGGTGGGTAATGGAG \\
Cathepsin D & TGTGGAGGACCTGATTGC & CGAAGACGACTGTGAAGC
\end{tabular}

The PCR conditions included an amplification cycle of $94^{\circ} \mathrm{C}$ for $12 \mathrm{~min} ; 40$ cycles of denaturation, amplification, and quantification for $15 \mathrm{~s}$ at $95^{\circ} \mathrm{C}$, $58-64^{\circ} \mathrm{C}$ for $30 \mathrm{~s}$, and finally $72^{\circ} \mathrm{C}$ for $25 \mathrm{~s}$. Also, melting curve analysis was performed at $65^{\circ} \mathrm{C}$ to $95^{\circ} \mathrm{C}$ with a gradual increase. RT-PCR assay was carried out in three separate analyses. Every sample was examined in duplicate.

\section{Statistical Analysis}

The results of the ELISA and real-time RT-PCR are presented as mean \pm SD of three separate experiments. Kolmogorov Smirnov test was used to check the normal distribution of the data. To compare ELF-PEMF-treated hRPE cultures and control groups, we used Mann-Whitney or $t$-test. $P<0.05$ was considered statistically significant.

\section{RESULTS}

\section{hRPE Cell Identification}

The RPE cells were cultured in a DMEM/F12 medium (1:1), containing FBS $10 \%(\mathrm{v} / \mathrm{V})$. After removing the culture medium at $80 \%$ confluence within one week, it was subjected to the mentioned ICC protocol. The cultured hRPE cells showed immunoreactivity for cytokeratin 8/18 (Figure 1A-1C) and RPE65 (Figure 1D-1F), confirming their identity.

\section{Cell Proliferation and Cell Death Evaluation}

Effects of ELF-PEMF on the cell proliferation and apoptosis of hRPE cells were examined by ELISA. The findings showed that ELF-PEMF did not influence cell proliferation (Figure 2). As well, no cytotoxic effect was reported in the treated cells in comparison with the controls (Figure 3 ).

\section{Gene Expression Analysis}

The expression levels of HIF-1 $\alpha$, CTGF, VEGFA, MMP-2, cathepsin-D, and E2F3 after ELF-PEMF exposure of hRPE cells in comparison with the controls were evaluated by real-time RT-PCR. Effect of ELF-PEMF on mRNA expression was evaluated in three intervals $(5,10$, and $15 \mathrm{~min})$. The expression level of all genes significantly reduced in hRPE cells in comparison with the controls after 5 min (Figure 4 and Figure 5, $\mathrm{P}<0.05$ ). At $10 \mathrm{~min}$, the expression levels of VEGFA and MMP-2 were significantly increased in hRPE cells after ELF-PEMF exposure compared to the controls. However, after $15 \mathrm{~min}$, only the expression level of E2F3 decreased while CTGF, VEGFA and MMP-2 were significantly increased in treated hRPE cells in comparison with the control group (Figure 6).

\section{DISCUSSION}

ELF-PEMF exposure had not any cytotoxic and proliferative effects on the hRPE cells, that in combination with negative impacts on the angiogenic factors, the future of this noninvasive treatment strategy for neovascular eye diseases will be promising. The balance between proangiogenic and antiangiogenic factors is essential for normal angiogenesis. However, in pathogenic conditions, the imbalance is perturbed. ${ }^{[30]}$ Pathological retinal angiogenesis induced by hRPE cells in diseases, such as AMD and DR, eventually leads to visual loss. Therefore, it is necessary to be controlled and treated. ${ }^{[31]}$

VEGFA as a key molecule in ocular diseases [32], is a downstream factor of HIF-1 transcription factor. HIF-1 can increase the expression of VEGFA that promotes cell proliferation and migration 

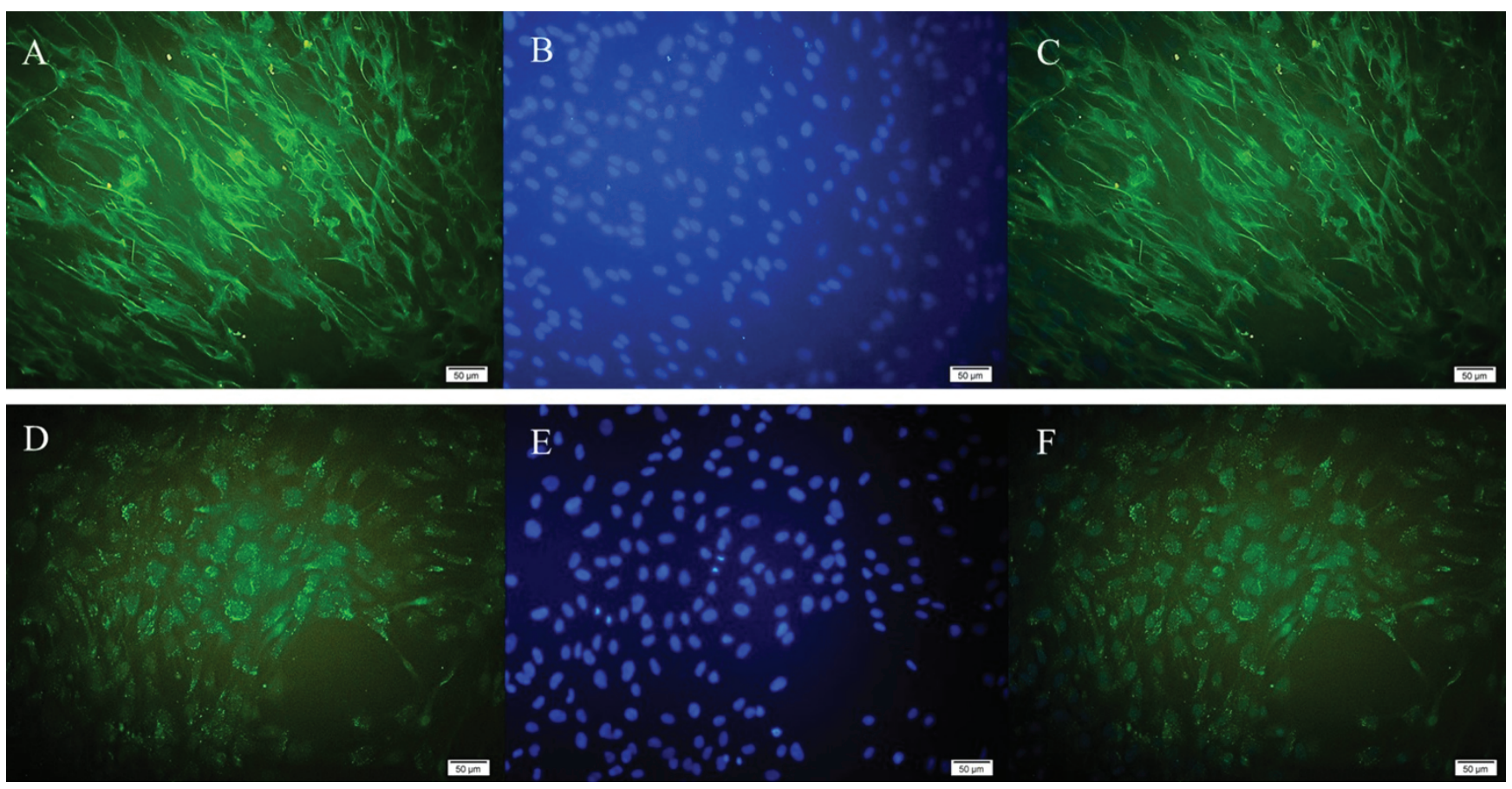

Figure 1. Immunocytochemistry of hRPE cells indicating RPE cell identity. Cytokeratin 8/18 expression confirms the epithelial origin of the cultures, and RPE65 expression confirms that isolated cells are RPE cells. (A) RPE cells stained positively for the fluoresceinisothiocyanate (FITC)-conjugated cytokeratin antibody (green). (B) Nuclei stained blue with 4,6-diamidino-2phenyindole dihydrochloride (DAPI). (C) Merged image (FITC-labeled cytokeratin and DAPI; 200X). (D) RPE cells stained positively for the RPE65 antibody (green). (E) DAPI-stained RPE cell nuclei (blue). (F) Merged image (FITC-labeled RPE65 and DAPI; $200 X)$.

\section{Cell Proliferation ELISA Assay}

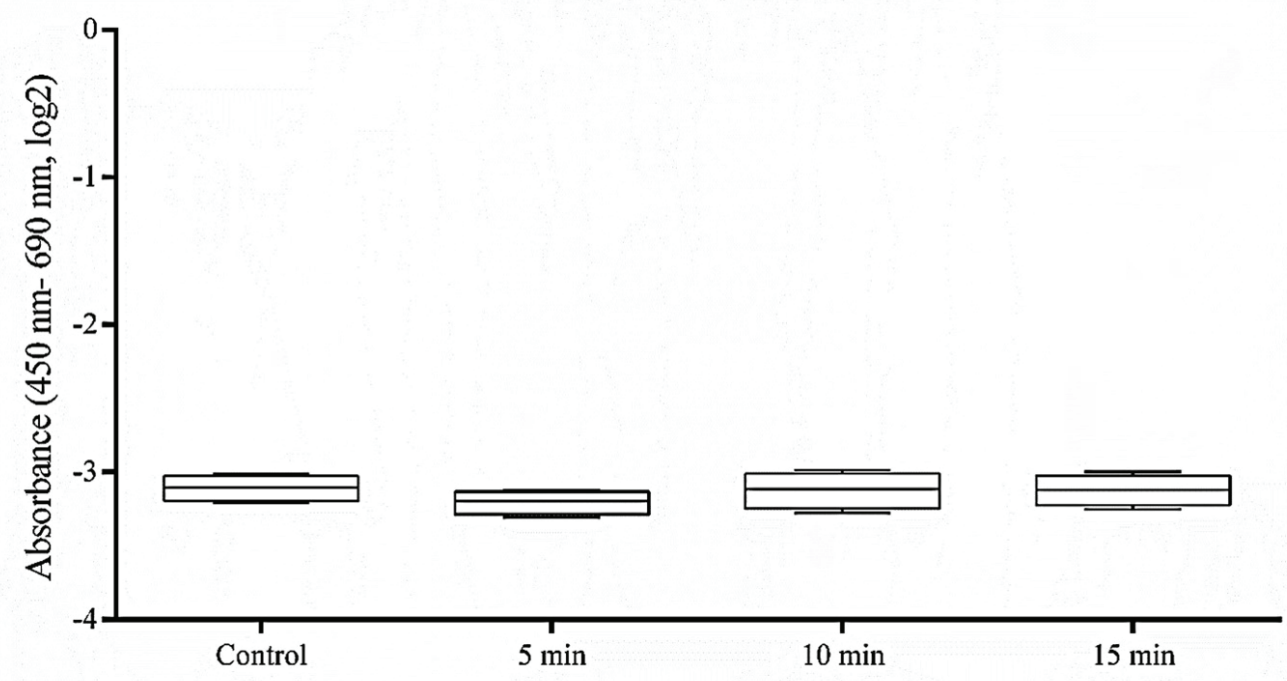

Figure 2. Effect of ELF-PEMF on the proliferation rate of hRPE cells. hRPE cells exposed to ELF-PEMF; After 7 days and each day 5,10 , and $15 \mathrm{~min}$ of exposure at a magnetic intensity of $15 \mathrm{mT}(120 \mathrm{~Hz}, 92 \mathrm{~V})$, Cultures were harvested and proliferation assay was performed according to the manufacturer's instructions for cell proliferation ELISA assay. Proliferation rate of hRPE cell cultures did not changed under exposure to ELF-PEMF compared to non-treated control cultures $(P>0.05)$. 


\section{Cell Death ELISA Assay}

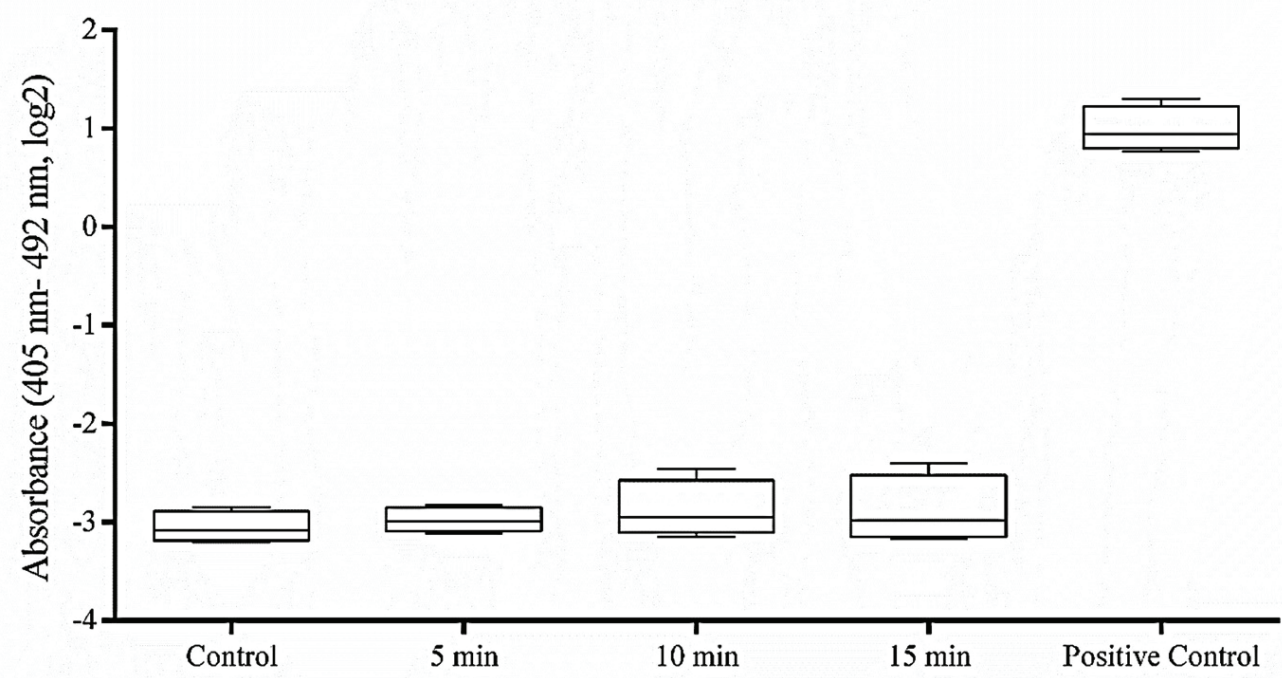

Figure 3. Exploring the cytotoxic effects of ELF-PEMF on hRPE cells. Exposure time on each day was 5, 10, and 15 min and was performed at a magnetic intensity of $15 \mathrm{mT}(120 \mathrm{~Hz}, 92 \mathrm{~V})$ during one week. After exposure, cultures were harvested and subjected to cell death assay according to the manufacturer's instructions for cell death ELISA assay. Results indicated that ELF-PEMF did not has any cytotoxic effects on the treated hRPE cells compared to the positive control provided by the kit $(P>0.05)$.

through its related receptors. ${ }^{[33]}$ In addition, VEGFA is an upstream factor of CTGF and can upregulate its expression, which is a proangiogenic factor in several organs. Furthermore, it is linked to pathological fibrosis, such as vitreoretinal disorders including AMD and DR..$^{[15,34,35]}$ It was demonstrated that in diabetic rats, the expression level of CTGF was upregulated in the retina. ${ }^{[36]}$ Moreover, the expression of many angiogenic mediators, such as cathepsins and MMPs, is induced by VEGFA and CTGF. ${ }^{[37,38]}$ In addition, in the early phases of angiogenic process, ECM degradation by MMPs and cathepsin proteases is commonly performed. ${ }^{[39]}$

There is an increasing interest in the therapeutic potential of ELF-PEMFs for patients with diseases associated with neovascularization. ${ }^{[27,40,41]}$ It was previously reported that ELF-PEMFs negatively affect angiogenesis in breast cancer. ${ }^{[42]}$ In addition, it was demonstrated that VEGFR2 expression and activation, which is an important factor in vascular formation by endothelial cells, decreased following ELF-PEMFs treatment. ${ }^{[26]}$

Moreover, it was shown that ELF-PEMFs activate stress proteins, including heat-shock proteins (e.g., HSP90, and HSP70), changing the half-life, activity or expression of proteins, such as VEGFR1 and VEGFR2. ${ }^{27,43-47]}$ In addition, it was demonstrated that ELF-PEMF stimulation significantly decreased the renal expression of VEGFA. ${ }^{[48]}$ In the current study, ELF-PEMF negatively affected the expression of VEGFA, HIF-1 $\alpha$, CTGF, MMP-2, cathepsin-D, and E2F3 as angiogenic factors. Therefore, ELF-PEMF can be investigated as a novel therapeutic approach for retinal neovascular disorders. The mentioned antiangiogenic effect was after 5-min treatment, at $10 \mathrm{~min}$, results were reversed and ELF-PEMF acted as an angiogenic agent! VEGFA and MMP-2 were increased significantly in the treated cultures. At $15 \mathrm{~min}$, in addition to VEGFA and MMP-2, CTGF significantly was increased compared to the untreated cultures. Based on the results, the effect of ELF-PEMF on hRPE cells is time-dependent. Besides, in different articles effects of ELF-PEMF was shown to be dependent on more parameters such as cell type, frequency and flux density. ${ }^{[48,49]}$ Emerging evidence suggests the use of ELF-PEMF in therapy still requires a lot of research.

\section{CONCLUSION}

We observed that ELF-PEMFs have significant inhibitory roles on the expression of angiogenic factors in the hRPE cells, as pivotal cells in ocular health and disease. Therefore, ELF-PEMFs can 


\section{Real-Time RT-PCR}

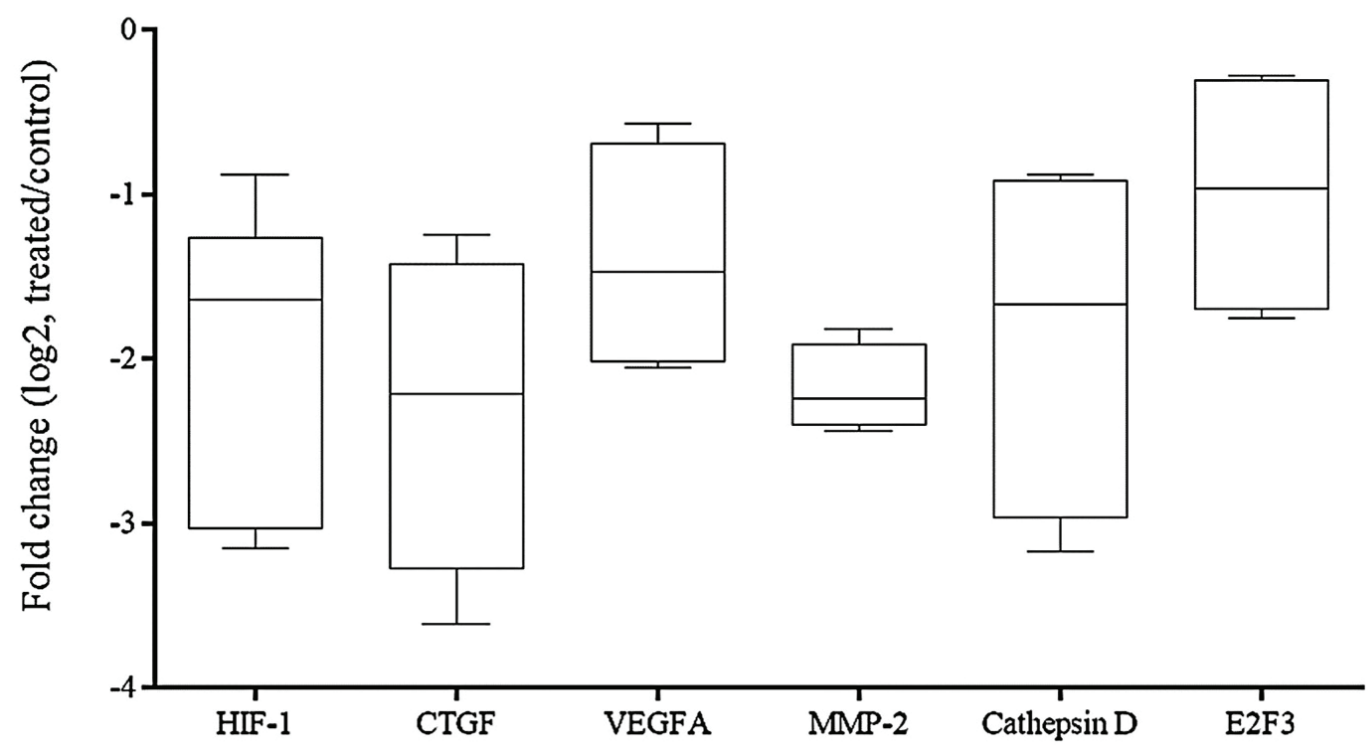

Figure 4. Box plot analysis of HIF-1 $\alpha$, CTGF, VEGFA, MMP-2, cathepsin D and E2F3 expression in hRPE cell cultures exposed to ELF-PEMF as treated cultures compared to hRPE cell cultures without ELF-PEMF as control cultures. After 5 min, RNA was extracted, and gene expression analysis was performed by quantitative real-time RT-PCR as described in the methods section. mRNA levels were normalized to GAPDH and presented as $\log 2$ fold change of the control values. Expression levels of all the genes were significantly reduced in the treated hRPE cells compared to the control cultures $(P<0.05)$.

\section{Real-Time RT-PCR}

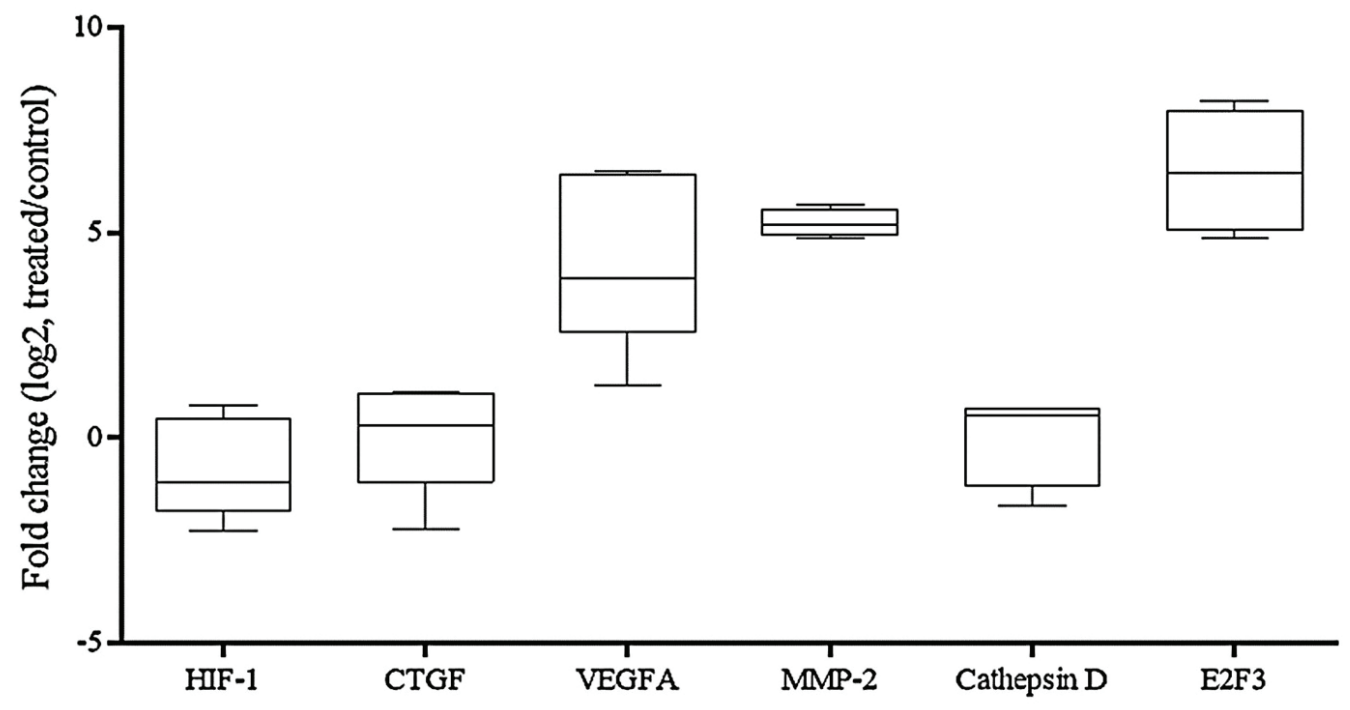

Figure 5. Box plot analysis of HIF-1 $\alpha$, CTGF, VEGFA, MMP-2, cathepsin D and E2F3 expression in hRPE cell cultures exposed to ELF-PEMF as treated cultures compared to hRPE cell cultures without ELF-PEMF as control cultures. After 10 min, RNA was extracted, and gene expression analysis was performed by quantitative real-time RT-PCR as described in the methods section. mRNA levels were normalized to GAPDH and presented as log2 fold change of the control values. Expression levels of VEGFA and MMP-2 were significantly increased in hRPE cells after ELF-PEMF exposure compared to the controls $(P<0.05)$. 


\section{Real-Time RT-PCR}

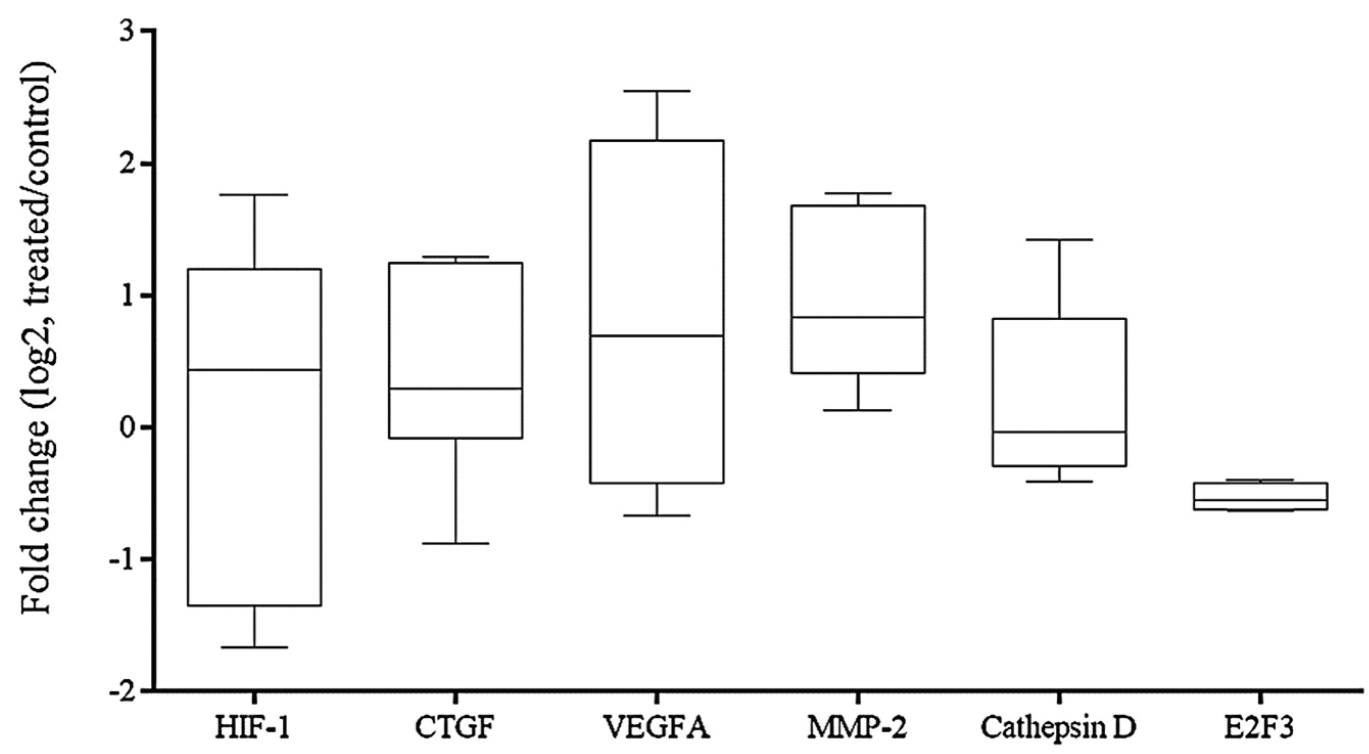

Figure 6. Box plot analysis of HIF-1 $\alpha$, CTGF, VEGFA, MMP-2, cathepsin D and E2F3 expression in hRPE cell cultures exposed to ELF-PEMF as treated cultures compared to hRPE cell cultures without ELF-PEMF as control cultures. After 15 min, RNA was extracted, and gene expression analysis was performed by quantitative real-time RT-PCR as described in the methods section. mRNA levels were normalized to GAPDH and presented as log2 fold change of the control values. Expression levels of CTGF, VEGFA and MMP-2 were significantly increased, while E2F3 was significantly decreased in treated hRPE cells compared to the controls $(P<0.05)$.

be used for therapeutic applications in ocular diseases, but field strengths, frequencies, and exposure times must be considered. Also, further studies should be done to evaluate important genes and factors altered by ELF-EMF in different settings and situations.

\section{Acknowledgements}

The authors express their gratitude to the Mazandaran University of Medical Sciences, Central Eye Bank of Iran, and Shahid Beheshti University of Medical Sciences for their collaborations.

\section{Financial Support and Sponsorship}

The current study has been derived from a research project funded by Stem Cell Research Center, Golestan University of Medical Sciences, Gorgan, Iran (Grant number: 950804171).

\section{Conflicts of Interest}

All authors declare that they have no conflicts of interests.

\section{REFERENCES}

1. Campochiaro PA. Molecular pathogenesis of retinal and choroidal vascular diseases. Prog Retin Eye Res 2015;49:67-81.

2. Zhang $Y$, Cai S, Jia $Y$, Qi C, Sun J, Zhang $H$, et al. Decoding noncoding RNAs: role of microRNAs and long noncoding RNAs in ocular neovascularization. Theranostics 2017;7:3155.

3. Wong EN, Chew AL, Morgan WH, Patel PJ, Chen FK. The use of microperimetry to detect functional progression in non-neovascular age-related macular degeneration: a systematic review. Asia Pac J Ophthalmol 2017;6:70-79.

4. Ehlken C, Guichard M-M, Schlunck G, Bühler AD, Martin G, Agostini HT. Expression of angiogenic and inflammatory factors in choroidal neovascularisation-derived retinal pigment epithelium. Ophthalmic Res 2019;61:174-182.

5. Bagheri A, Soheili ZS, Ahmadieh H, Samiei S, Sheibani $\mathrm{N}$, Astaneh SD, et al. Simultaneous application of bevacizumab and anti-CTGF antibody effectively suppresses proangiogenic and profibrotic factors in human RPE cells. Mol Vis 2015;21:378-390.

6. Heidari R, Soheili ZS, Samiei S, Ahmadieh H, Davari M, Nazemroaya F, et al. Alginate as a cell culture substrate for growth and differentiation of human retinal pigment epithelial cells. Appl Biochem Biotechnol 2015;175:2399_ 2412.

7. Sanie-Jahromi F, Ahmadieh $H$, Soheili ZS, Davari M, Ghaderi S, Kanavi MR, et al. Enhanced generation of retinal 
progenitor cells from human retinal pigment epithelial cells induced by amniotic fluid. BMC Res Notes 2012;5:182.

8. Heirani-Tabasi A, Toosi S, Mirahmadi M, Mishan MA, Bidkhori HR, Bahrami AR. Chemokine receptors expression in MSCs: comparative analysis in different sources and passages. Tissue Eng Regen Med 2017;14:605-615.

9. Mirahmadi M, Ahmadiankia N, Naderi-Meshkin $\mathrm{H}$, HeiraniTabasi A, Bidkhori HR, Afsharian P, et al. Hypoxia and laser enhance expression of SDF-1 in muscles cells. Cell Mol Biol 2016;62:31-37.

10. Heirani-Tabasi A, Mirahmadi M, Mishan MA, NaderiMeshkin H, Toosi S, Matin MM, et al. Comparison of the effects of hypoxia-mimicking agents on migration-related signaling pathways in mesenchymal stem cells. Cell Tissue Bank 2020;21:643-653.

11. André $H$, Tunik $S$, Aronsson M, Kvanta A. Hypoxiainducible factor- $1 \alpha$ is associated with sprouting angiogenesis in the murine laser-induced choroidal neovascularization model. Invest Ophthalmol Vis Sci 2015;56:6591-6604.

12. Ved N, Hulse RP, Bestall SM, Donaldson LF, Bainbridge JW, Bates D. Vascular endothelial growth factor-A165b ameliorates outer-retinal barrier and vascular dysfunction in the diabetic retina. Clin Sci 2017;131:1225-1243.

13. Sun D, Nakao S, Xie F, Zandi S, Bagheri A, Kanavi MR, et al. Molecular imaging reveals elevated VEGFR-2 expression in retinal capillaries in diabetes: a novel biomarker for early diagnosis. FASEB J 2014;28:3942-3951.

14. Wheler JJ, Janku F, Naing A, Li Y, Stephen B, Zinner R, et al. TP53 Alterations correlate with response to VEGF/VEGFR inhibitors: implications for targeted therapeutics. Mol Cancer Ther 2016;15:2475-2485.

15. Klaassen I, van Geest RJ, Kuiper EJ, van Noorden CJ, Schlingemann RO. The role of CTGF in diabetic retinopathy. Exp Eye Res 2015;133:37-48.

16. Ishizaki E, Takai S, Ueki M, Maeno T, Maruichi M, Sugiyama $\mathrm{T}$, et al. Correlation between angiotensinconverting enzyme, vascular endothelial growth factor, and matrix metalloproteinase- 9 in the vitreous of eyes with diabetic retinopathy. Am J Ophthalmol 2006;141:129-134.

17. Vizovišek M, Fonović $M$, Turk B. Cysteine cathepsins in extracellular matrix remodeling: Extracellular matrix degradation and beyond. Matrix Biol 2018;75-76:141-159.

19. Shastry BS. Genetic susceptibility to advanced retinopathy of prematurity (ROP). J Biomed Sci 2010;17:69.

19. Chiavenna S, Jaworski J, Vendrell A. State of the art in anticancer mAbs. J Biomed Sci 2017;24:15.

20. Ye W. The complexity of translating anti-angiogenesis therapy from basic science to the clinic. Dev Cell 2016;37:114-125.

21. Iwase T, Fu J, Yoshida T, Muramatsu D, Miki A, Hashida $\mathrm{N}$, et al. Sustained delivery of a HIF-1 antagonist for ocular neovascularization. J Control Release 2013;172:625-633.

22. Barnett JM, McCollum GW, Fowler JA, Duan JJ-W, Kay JD, Liu R-Q, et al. Pharmacologic and genetic manipulation of MMP-2 and-9 affects retinal neovascularization in rodent models of OIR. Invest Ophthalmol Vis Sci 2007;48:907915.

23. Markov MS. Magnetic field therapy: a review. Electromagn Biol Med 2007;26:1-23.
24. Ehnert S, Fentz A-K, Schreiner A, Birk J, Wilbrand B, Ziegler $P$, et al. Extremely low frequency pulsed electromagnetic fields cause antioxidative defense mechanisms in human osteoblasts via induction of $\mathrm{O}_{2}^{-}$and $\mathrm{H}_{2} \mathrm{O}_{2}$. Sci Rep 2017;7:14544.

25. Kanavi MR, Tabeie F, Sahebjam F, Poursani N, Jahanbakhsh N, Paymanpour P, et al. Short-term effects of extremely low-frequency pulsed electromagnetic field and pulsed low-level laser therapy on rabbit model of corneal alkali burn. Exp Eye Res 2016;145:216-223.

26. Delle Monache $S$, Angelucci A, Sanità P, lorio R, Bennato $F$, Mancini F, et al. Inhibition of angiogenesis mediated by extremely low-frequency magnetic fields (ELF-MFs). PLoS ONE 2013;8:e79309.

27. Akbarnejad Z, Eskandary H, Vergallo C, NematollahiMahani SN, Dini L, Darvishzadeh-Mahani F, et al. Effects of extremely low-frequency pulsed electromagnetic fields (ELF-PEMFs) on glioblastoma cells (U87). Electromagn Biol Med 2017;36:238-247.

28. Nasrabadi N, Soheili ZS, Bagheri A, Ahmadieh $H$, Amizadeh $Y$, Sahebjam F, et al. The effects of electromagnetic fields on cultured human retinal pigment epithelial cells. Bioelectromagnetics 2018;39:585-594.

29. Campochiaro PA, Aiello LP, Rosenfeld PJ. Anti-vascular endothelial growth factor agents in the treatment of retinal disease: from bench to bedside. Ophthalmology 2016;123:S78-S88.

30. Campochiaro PA. Ocular neovascularization. J Mol Med 2013;91:311-321.

31. Miller JW, Le Couter J, Strauss EC, Ferrara N. Vascular endothelial growth factor a in intraocular vascular disease. Ophthalmology 2013;120:106-114.

32. Niu G, Chen X. Vascular endothelial growth factor as an anti-angiogenic target for cancer therapy. Curr Drug Targets 2010;11:1000-1017.

33. Ungvari Z, Valcarcel-Ares MN, Tarantini S, Yabluchanskiy A, Fülöp GA, Kiss T, et al. Connective tissue growth factor (CTGF) in age-related vascular pathologies. Geroscience 2017;39:491-498.

34. Akbari Kordkheyli V, Khonakdar Tarsi A, Mishan MA, Tafazoli A, Bardania H, Zarpou S, et al. Effects of quercetin on microRNAs: a mechanistic review. J Cell Biochem 2019;120:1-15.

35. Yang $\mathrm{H}$, Huang $\mathrm{Y}$, Chen $\mathrm{X}$, Liu J, Lu Y, Bu L, et al. The role of CTGF in the diabetic rat retina and its relationship with VEGF and TGF- $\beta 2$, elucidated by treatment with CTGFsiRNA. Acta Ophthalmol 2010;88:652-659.

36. Wu W, Zaal EA, Berkers CR, Lemeer S, Heck AJ. CTGF/VEGFA-activated fibroblasts promote tumor migration through micro-environmental modulation. Mol Cell Proteomics 2018;17:1502-1514.

37. Mongiat M, Andreuzzi E, Tarticchio G, Paulitti A. Extracellular matrix, a hard player in angiogenesis. Int J Mol Sci 2016;17:1822.

38. Sivakumar P, Kitson C, Jarai G. Modeling and measuring extracellular matrix alterations in fibrosis: challenges and perspectives for antifibrotic drug discovery. Connect Tissue Res 2019;60:62-70.

39. Vadalà M, Morales-Medina JC, Vallelunga A, Palmieri B, Laurino C, lannitti T. Mechanisms and therapeutic effectiveness of pulsed electromagnetic field therapy in oncology. Cancer Med 2016;5:3128-3139. 
40. Lucia U, Ponzetto A. Some thermodynamic considerations on low frequency electromagnetic waves effects on cancer invasion and metastasis. Physica A 2017;467:289295.

41. Cameron IL, Markov MS, Hardman WE. Optimization of a therapeutic electromagnetic field (EMF) to retard breast cancer tumor growth and vascularity. Cancer Cell Int 2014;14:125.

42. Yang X-S, He G-L, Hao Y-T, Xiao Y, Chen C-H, Zhang G-B, et al. Exposure to $2.45 \mathrm{GHz}$ electromagnetic fields elicits an HSP-related stress response in rat hippocampus. Brain Res Bull 2012;88:371-378.

43. Robertson JA, Thomas AW, Bureau Y, Prato FS. The influence of extremely low frequency magnetic fields on cytoprotection and repair. Bioelectromagnetics 2007;28:16-30.

44. Delle Monache S, Alessandro R, lorio R, Gualtieri G, Colonna R. Extremely low frequency electromagnetic fields (ELF-EMFs) induce in vitro angiogenesis process in human endothelial cells. Bioelectromagnetics 2008;29:640-648.
45. Bruns AF, Yuldasheva N, Latham AM, Bao L, PelletMany C, Frankel P, et al. A heat-shock protein axis regulates VEGFR2 proteolysis, blood vessel development and repair. PLoS ONE 2012;7:e48539.

46. Mousavi M, Baharara J, Shahrokhabadi K. The synergic effects of Crocus sativus L. and low frequency electromagnetic field on VEGFR2 gene expression in human breast cancer cells. Avicenna J Med Biotechnol 2014;6:123.

47. Li $F$, Lei $T$, Xie $K$, Wu X, Tang $C$, Jiang $M$, et al. Effects of extremely low frequency pulsed magnetic fields on diabetic nephropathy in streptozotocin-treated rats. Biomed Eng Online 2016;15:8.

48. Oladnabi $M$, Bagheri A, Rezaei Kanavi M, Azadmehr A, Kianmehr A. Extremely low frequency-pulsed electromagnetic fields affect proangiogenic-related gene expression in retinal pigment epithelial cells. Iran $J$ Basic Med Sci 2019;22:128-133.

49. D’Angelo C, Costantini E, Kamal M, Reale M. Experimental model for ELF-EMF exposure: concern for human health. Saudi J Biol Sci 2015;22:75-84. 